\title{
Discussion on the Teaching Method of Using Cloud Computing Technology to Improve the Stability Training of the Trunk Pillar in College Physical Education Curriculum
}

\author{
Yongan Wang $\mathbb{D}^{1,2}$ and Yun Feng $\mathbb{D}^{2}$ \\ ${ }^{1}$ Graduate School, Capital University of Physical Education and Sport, Beijing 100191, China \\ ${ }^{2}$ The Faculty of Physical Education, China West Normal University, Nanchong 637009, Sichuan, China \\ Correspondence should be addressed to Yun Feng; fengyun1991@cwnu.edu.cn
}

Received 5 October 2021; Revised 15 November 2021; Accepted 24 November 2021; Published 29 January 2022

Academic Editor: Punit Gupta

Copyright (C) 2022 Yongan Wang and Yun Feng. This is an open access article distributed under the Creative Commons Attribution License, which permits unrestricted use, distribution, and reproduction in any medium, provided the original work is properly cited.

\begin{abstract}
This work is to develop an effective trunk support stability training program, thereby improving the quality of college physical education. First, the advantages and characteristics of trunk support stability training are analyzed under the physiological basis and biomechanical basis of trunk support stability training. Then, the trunk support stability training program is developed to train the stability, strength, and balance of the sprint athletes' shoulder, trunk, and buttocks musculature, as well as the control ability of the limbs. Twenty undergraduates in the track and field sprint special class of Xi'an Physical Education University are recruited and rolled into experimental group and control group, each with 10 students, and trained for 8 weeks. Finally, functional movement screen (FMS), postshot throw, level-ten stepping tests, and sprint tests $(30 \mathrm{~m}, 60 \mathrm{~m}$, and $100 \mathrm{~m})$ are performed. The results show that before the start of the experiment, there is no considerable difference in the score comparison between experimental group and control group in different test items $(P>0.05)$. After the experiment, the test scores of level-ten stepping, postshot throw, and $30 \mathrm{~m}, 60 \mathrm{~m}$, and $100 \mathrm{~m}$ sprint of experimental group are remarkably different within the group $(P<0.05)$. In addition, the level-ten stepping and $60 \mathrm{~m}$ and $100 \mathrm{~m}$ sprint scores of experimental group and control group have great differences between the groups, indicating that the trunk support stability training program formulated in this work has a notable effect on college physically educated students.
\end{abstract}

\section{Introduction}

With the rapid development of society, economy, and science and technology, the continuous progress of competitive sports has been promoted, which has led to the formation of fierce competition among many sports [1]. Under the combined action of many factors, the competitive level of sports athletes has also been continuously improved, and the dynamic performance of many athletes is basically close to the limit of human beings. It is because of the need for the comprehensive development of athletes' competitiveness. Moreover, higher and higher requirements for special sports capabilities are also important reasons, which are very important influencing factors [2, 3]. Through scientific training, athletes strive to achieve excellent results in sports competitions, but they must also avoid physical injury as much as possible [4]. Based on the basic theory of modern sports function training, the performance of athletes is attributed to different sports techniques, and the basis of controlling body posture and ensuring sports quality is the stability of trunk support [5].

The concept of trunk support stabilization first appeared in Europe and was first used in the medical field to treat low back pain and chiropractic. Researchers first proposed that the components of the trunk supports were the spine, thoracic-abdominal cavity, and erector spinal muscles. The erector spinae can absorb external forces to maintain the elasticity of the spine and its central position. The benign feedback can maintain the stability of the trunk supports and avoid low back pain [6]. At the end of the twentieth century, 
TABle 1: Advantages of trunk support stability training.

\begin{tabular}{|c|c|}
\hline Advantages & Main content \\
\hline Status advan & nd training of deep mu \\
\hline Theoretical ad & theor \\
\hline $\begin{array}{l}\text { Dimensional } \\
\text { advantage }\end{array}$ & $\begin{array}{c}\text { It makes multidimensional connections, optimizes the transmission of strength, and improves the coordination } \\
\text { between body muscles }\end{array}$ \\
\hline
\end{tabular}

the theory of trunk support stability was used in sports rehabilitation and competitive sports. The strength of football players' trunk supports was tested, and different parts of the trunk were affected by the training intensity. The strength of the torso pillar played a vital role in promoting the action performance of football players [7]. The key to athletes' ability to transmit power and performance smoothly is having a strong and stable core. Trunk support stability training was an indispensable training method for athletes [8]. In China's competitive sports, teams such as the national team and the provincial team will conduct trunk support and stability training. Through this training, remarkable results have been achieved in swimming and track and field. Some researchers pointed out that more muscle fibers could be generated through training to solve unstable factors of the trunk, and the nervous system could also be trained to react quickly and obtain precise control capabilities. However, under normal circumstances, trunk support and stability training are difficult. Even advanced athletes need to train step by step to improve their ability. Trunk support stability training can promote the acquisition of special sports skills [9]. At present, there are relatively few research studies on sprint athletes' trunk support and stability training in the field of track. There are only studies on the accelerated running technology of sprint athletes but very little research on the special abilities of sprint athletes.

The physiological and biomechanical basis of trunk support stability training is analyzed, and a special trunk support stability training program for college sports students is innovatively formulated. Moreover, it is compared with the traditional trunk strength training program, to verify the feasibility and effectiveness of the program and provide experimental basis for improving the quality of college physical education.

\section{Methods}

2.1. The Scientific Mechanism of Trunk Support Stability Training. The core function of trunk support and stability training is to improve the strength, balance, and stability of the muscles between the shoulders and buttocks. The main feature is that it can maintain the stability and erection of the athlete's spine and pelvis and improve the stability and balance of the body, thereby greatly improving the efficiency of energy transfer from the trunk to the limbs. In addition, it can prevent physical injuries in sports and improve the sports performance of athletes [10]. The main purpose of this study is improving the subjects' basic abilities such as stability, strength, balance, and speed, as well as gradually improving the relationship between the trunk muscles and the limbs, thus enhancing the motor function of the limbs. The advantages of trunk support stability training compared with traditional waist and abdominal muscle strength training are shown in Table 1.

According to the main idea of sports training, the training method of trunk support stability is an actual practice method based on the stability and flexibility of human body function [11]. In a specific sports environment, practice methods should be selected according to the characteristics of the athlete's core muscle tissue, and special techniques that adapt to specificity should be developed under the development of stable balance ability. Studies pointed out that trunk support stability training can improve balance and stability, but it cannot improve running balance and stability [12], which meant that in the trunk support and stability training, the training program should be matched with special techniques.

The physiological basis of trunk support stability training includes three parts: skeletal ligament system, muscle power system, and nerve control system. The functions of each system are shown in Table 2.

To develop an efficient trunk support stability training program, it is necessary to analyze its biomechanical mechanism. In strength training, the muscles at both ends of the bones tend to work in the middle. If one end is fixed, the energy formed by the work at the other end will gradually approach it [13]. Therefore, to avoid the occurrence of redundant movements, athletes need to arrange training content reasonably and effectively and train the proximal muscles fixedly, letting the distal muscles cooperate and produce activities, so that the muscles contract faster. To realize such effect and state, the coach must be able to accurately grasp and control the content of the exercise during the training process [14]. If there is no scientifically formulated plan, it will cause other muscles to participate in the activity, forming a compensation effect and causing the athlete to make redundant movements. The human body consumes too much energy, which affects the normal performance of athletes' sports skills and causes sports injuries [15].

Trunk support stability training on sprint athletes can gradually increase the strength of the athlete's trunk support, stabilizes the center of gravity, improves running posture, enhances energy efficiency, and ultimately improves sports performance [16]. The imbalance of the body is adjusted by improving the muscle strength of weak parts of sprint athletes so as to prevent sports injuries.

\subsection{Trunk Support Stability Training Plan Formulation.} The sprint special trunk support and stability training are aimed at the stability, strength, and balance of sprint athletes' 
TABle 2: Physiological basis of trunk support stability training.

\begin{tabular}{|c|c|}
\hline Different systems & Main functions \\
\hline $\begin{array}{l}\text { Bone ligament } \\
\text { system }\end{array}$ & $\begin{array}{l}\text { The spine is made up of } 26 \text { vertebrae that are connected to ligaments around the spine to maintain stability in } \\
\text { physical activity. When the body moves, its weight and external momentum are transferred from the spine to the } \\
\text { extremities. The soft tissue between the vertebrae increases the flexibility of the spine, thereby increasing the range of } \\
\text { motion of the entire spine. }\end{array}$ \\
\hline $\begin{array}{l}\text { Muscle strength } \\
\text { system }\end{array}$ & $\begin{array}{l}\text { Controlling the range of motion and stability of the spine can produce great force. Performing centripetal } \\
\text { movement activates muscles and helps control the angle and stability of the spine. }\end{array}$ \\
\hline $\begin{array}{l}\text { Neural control } \\
\text { system }\end{array}$ & $\begin{array}{l}\text { Constantly improving the body's adaptations can improve control of the limbs. The nerves of the human body can } \\
\text { control the adjustment of the trunk muscles in the unstable state and tend to stabilize, thus speeding up the nervous } \\
\text { system activity and improving the motor ability. }\end{array}$ \\
\hline
\end{tabular}

TABLE 3: Training plan of experimental group and control group.

\begin{tabular}{|c|c|c|}
\hline Time & Group & Content \\
\hline Monday & $\begin{array}{l}\text { Experimental } \\
\quad \text { group } \\
\text { Control group }\end{array}$ & $\begin{array}{l}\text { Basic }(5 \mathrm{~min}) \longrightarrow \text { jogging }+ \text { stretching }+ \text { sprint }+ \text { targeted exercise }(25 \text { min }) \longrightarrow \text { trunk support } \\
\text { stability training }(20 \text { min })+\text { sprint training }(30 \text { min }) \longrightarrow \text { static stretching }(5 \text { min }) \text {. } \\
\text { Basic } \longrightarrow \text { running }+ \text { stretching }+ \text { sprint }+ \text { targeted exercises } \longrightarrow \text { traditional trunk strength } \\
\text { training }+ \text { sprint training } \longrightarrow \text { static stretching; the training time is the same as experimental group. }\end{array}$ \\
\hline $\begin{array}{l}\text { Wednesday and } \\
\text { Friday }\end{array}$ & $\begin{array}{l}\text { Experimental } \\
\quad \text { group } \\
\text { Control group }\end{array}$ & $\begin{array}{l}\text { Basic }(5 \mathrm{~min}) \longrightarrow \text { jogging }+ \text { stretching }+ \text { sprint }+ \text { targeted exercise }(40 \text { min }) \longrightarrow \text { trunk support } \\
\text { stability training }(30 \text { min })+\text { sprint training }(45 \text { min }) \longrightarrow \text { jogging }+ \text { static stretching }(10 \text { min }) \text {. } \\
\text { Basic } \longrightarrow \text { jogging }+ \text { stretching }+ \text { sprint }+ \text { targeted exercises } \longrightarrow \text { traditional trunk strength } \\
\text { training }+ \text { sprint training } \longrightarrow \text { jogging }+ \text { static stretching, the same time as experimental group. }\end{array}$ \\
\hline
\end{tabular}

shoulder, trunk, and hip musculature, as well as the control ability of the limbs [17]. Studies show that when athletes hear a gun, they respond quickly through nerve conduction and start into the acceleration stage. The first starting steps are particularly important, requiring the extent of the torso to lean forward in the process of running. Therefore, it focuses on the ability of the nervous system to mobilize and control deep muscles and improve the coordination ability of sprint athletes with multimuscle groups and multiplanar joints [18]. The subjects selected in the experimental plan are 20 undergraduates in the track and field sprint special class of Xi'an Physical Education University, which are rolled into an experimental group and a control group, with 10 students each. There are eight weeks of training, three times a week (Monday, Wednesday, and Friday), and the three-day training plan is shown in Table 3.

(1) The trunk support strength training of experimental group includes hip training (gluteal bridge training, kneeling hip abduction, and Swiss ball-clip ball to hip), spine and lumbar training (push bridge, side bridge, and Russian rotation), and shoulder training (Bosu ball-push-ups and combined stretching).

There are three kinds of hip training. First is gluteal bridge training. Subjects lie on their back with their knees bent 90 degrees and then lift their hips, hips, waist, lower back, and midback in turn. Shoulders and upper back touch the ground, and upper side of upper body tilts and stabilizes. When the subject has mastered the weight, he can increase the amount and strength of the weight by reducing the support point, raising the other leg to straighten or bend the leg, and adding unstable equipment. Second is kneeling position hip abduction. The body is in the shape of a fourlegged stool, kneeling, and hooked feet, with the left leg bent and the knee 90 degrees. With the toe abduction, it returns to the starting position. Then, right leg is slowly lifted to the right so does the left leg. As the subject improves, the bent leg can be changed into a straight leg to increase the power of the movement. Third is Swiss ball-pinch ball hip turn. The subject should lie on the back, clamp the Swiss ball between heel and hamstring, clamp the ball between left hip, and return to starting position clamp the ball between right hip.

There are three kinds of spinal and lumbar training. First is bending bridge. The feet and elbows are on the ground, front feet are on the ground, and back of the body is on a plane. After the subjects master the static position, the load can be gradually increased. Second is side bridge. The elbow and feet are on the ground, hips are off the floor, and body is in a diagonal line. After the subject has mastered the static side bridge movement, the difficulty and strength can be increased by raising the upper arms and legs or adding unstable equipment such as balance pads and Bosu balls. Third is the Russian twist. The subject should lie on the Swiss ball with his legs bent 90 degrees and his shoulder blades touching the ball. He should straighten the arms, keep hands together, tighten the abdominal muscles, and keep torso and thighs parallel to the floor. Then, turn right until the hands are parallel to the floor and return to the starting position and work backwards.

Shoulder training includes Bosu ball-push up (push up with Bosu ball support) and combination stretch (feet are shoulder-width apart, knees bent, arms in T-Y-W-L position, the instability equipment is increased as appropriate, and the strength is gradually increased).

The limbs are trained for the vertical throw (lifting the ball over the head and dropping it vertically to the ground), side throw (holding the ball in both hands and throwing it 
TABLE 4: Basic Information for control students.

\begin{tabular}{lccc}
\hline Stature & Weight & Age & Years of exercise \\
\hline 179 & 83 & 24 & 4 \\
176 & 70 & 23 & 4 \\
184 & 80 & 23 & 5 \\
174 & 65 & 24 & 5 \\
185 & 75 & 25 & 6 \\
178 & 68 & 21 & 5 \\
181 & 73 & 20 & 5 \\
177 & 69 & 21 & 5 \\
175 & 63 & 22 & 4 \\
172 & 61 & 23 & 5 \\
\hline
\end{tabular}

TABLE 5: Basic information of students in the experimental group.

\begin{tabular}{lccc}
\hline Stature & Weight & Age & Years of exercise \\
\hline 181 & 83 & 20 & 5 \\
176 & 67 & 21 & 6 \\
177 & 75 & 22 & 5 \\
174 & 67 & 24 & 5 \\
183 & 69 & 23 & 4 \\
173 & 63 & 23 & 5 \\
175 & 66 & 24 & 4 \\
179 & 83 & 25 & 5 \\
178 & 70 & 21 & 4 \\
182 & 80 & 20 & 5 \\
\hline
\end{tabular}

sideways against the wall with toe forward), and squatting with weight on one leg (with left leg standing, right leg bent, right foot lifted back on the Swiss ball, the barbell is held with both hands and squat on the knees, and the tasks are alternately completed).

(2) The traditional trunk strength training methods in control group include sit-ups, supine alternating leg lifts, flexion and straight leg abdominal tucks, barbell high turns, and side bends of the weight bearing body.

2.3. Experimental Testing and Data Analysis Tools. (1) Test indicators in the experiment are as follows. The first is FMS test [19], which is used to evaluate the quality of the action mode. The subjects' ability to control and stabilize their movements is observed through seven basic action modes. The second is postshot throw and level-ten stepping, which reflect the unique strength qualities of sprint athletes, the continuous explosive ability of the lower limbs, and the strength of the upper limbs. In addition, they also reflect the upper and lower limb coordination ability and power chain transmission ability [20]. The third is the sprint test $(30 \mathrm{~m}, 60 \mathrm{~m}$, and $100 \mathrm{~m})$, which reflects the subjects' starting ability, acceleration ability, and sprint conversion ability.

(2) SPSS 26.0 is employed to input and analyze experimental data. Paired sample $T$ test is performed to compare the differences within group before and after the experiments. Independent sample $T$ test is used to compare between groups, expressed by mean and variance. $P<0.05$ represents statistical significance.

\section{Results and Discussion}

\subsection{Application Effect Evaluation \\ 3.1.1. Research Subject}

(1) Experimental Group. 10 subjects are selected for trunk support strength training. See Table 4 for the specific information.

(2) Control Group. 10 subjects are selected for traditional trunk strength training. See Table 5 for the specific information.

3.1.2. Research Methods. FMS test, postshot throw, level-ten long jump test, and sprint test are performed on the subjects in experimental group and control group.

3.1.3. Mathematical Statistics Method. In this paper, experimental data were input and statistically analyzed using SPSS17.0, and paired sample $T$ test was used for the pre- and posterior comparisons of the same group and independent sample $T$ test for the comparison between the two groups. The results are expressed as mean and variance (M sergeant SD) and are statistically significant as $P<0.05$.

\subsection{Experimental Results}

3.2.1. Comparison of Test Indicators between the Two Groups before the Experiment. Before the experiment, FMS, postshot throw, level-ten long jump, and sprint tests are performed on the subjects in experimental group and control group. The results are shown in Figure 1.

Figure 1 shows that before the experiment, the scores of the experimental group and the control group in the FMS (a) test were $17.78 \pm 1.48$ and $18.01 \pm 1.78$, respectively. In the FMS (b) test, the scores were $16.78 \pm 2.35$ and $17.94 \pm 1.83$, respectively. There was no significant difference between the two groups $(P>0.05)$. The scores of the two groups were $(29.55 \pm 1.38$ and $28.28 \pm 1.46)$ and $(15.16 \pm 1.23$ and $14.98 \pm 1.02)$, respectively, with no significant difference $(P>0.05)$. In sprint test $C$, the speeds of the experimental group and the control group in the $30 \mathrm{~m}$ test were $3.87 \pm 0.08$ and $3.89 \pm 0.09$, respectively. In the $60 \mathrm{~m}$ test, the speeds were $6.97 \pm 0.22$ and $6.99 \pm 0.09$, respectively. In the $100 \mathrm{~m}$ test, the velocities were $11.22 \pm 0.18$ and $11.33 \pm 0.15$, respectively, with no significant difference $(P>0.05)$.

3.2.2. FMS Test Results of the Two Groups before and after the Experiment. FMS test results of experimental group and control group are compared before and after the experiment. The results are shown in Figure 2.

Figure 2 shows that the left FMS test score of subjects in experimental group increases from 17.78 to 19.61 , with an increase of 1.83 points, and there is dramatical difference in comparison $(P<0.01)$. The right FMS test scores of subjects in experimental group increase from 16.78 to 19.44, with an 


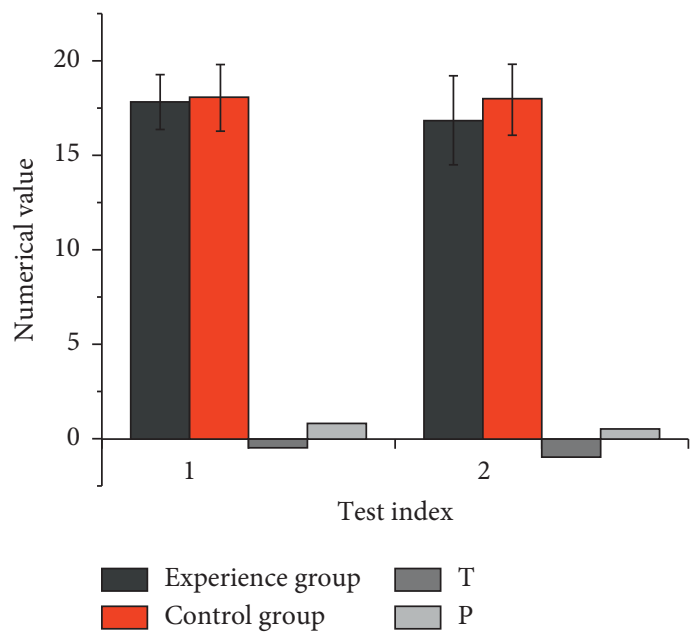

(a)

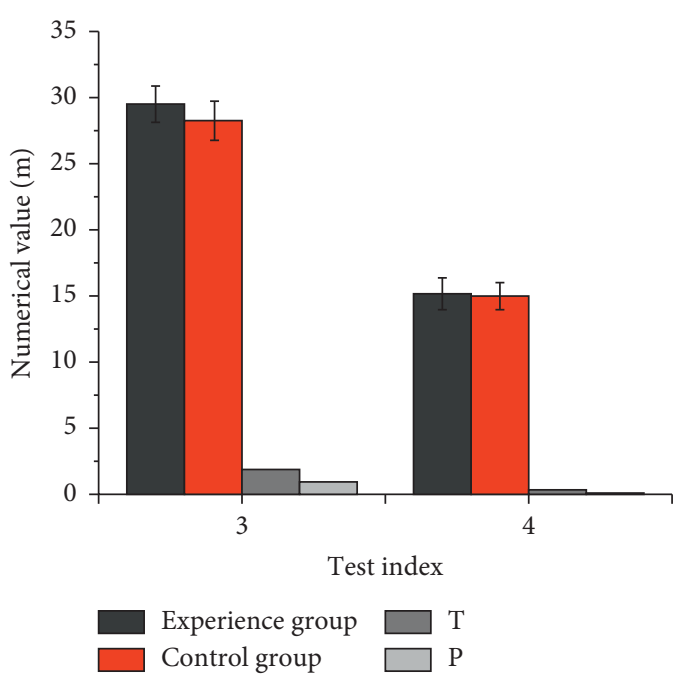

(b)

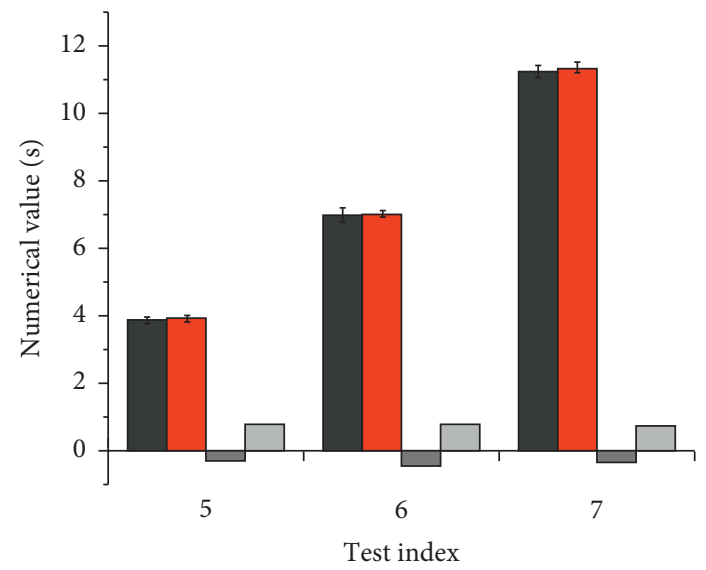

Experience group Control group

(c)

FIGURE 1: Comparison of the test results between the experimental group and the control group before the experiment. (a) FMS: 1: left, 2: right; (b) 3: level-ten long jump, 4: shoot; (c) 5:30 m, 6:60 m, 7:100 m.

increase of 2.66, with obvious difference $(P<0.01)$. The left FMS test score of control group increases from 18.01 to 18.72, and the right FMS test score of the control subjects increases from 17.94 to 18.78 , with substantial difference $(P<0.01)$. It means that both trunk support and stability training and traditional trunk strength training can improve subjects' FMS performance. The difference between the two groups is not great $(P>0.05)$, but the improvement of experimental group is obviously greater than that of control group.

\subsubsection{The Strength Test Results of the Two Groups before and} after the Experiment. The level-ten stepping and postshot throw test results of experimental group and control group are compared, and the results are shown in Figure 3.

Figure 3 shows that for the subjects in experimental group, the level-ten stepping increases from $28.55 \pm 1.34$ to $29.15 \pm 1.23$, and the contrast is notably different $(P<0.05)$.
The postshot throw increases from $14.01 \pm 1.97$ to $14.77 \pm 1.72$, and the contrast is greatly different $(P<0.05)$. For the subjects in control group, the level-ten stepping increases from $27.28 \pm 1.46$ to $27.66 \pm 1.29$, and there is no remarkable difference $(P>0.05)$. The postshot throw increases from $14.01 \pm 0.95$ to $14.25 \pm 1.15$, without considerable difference $(P>0.05)$. In addition, there is dramatical difference in the level-ten stepping results between the two groups $(P<0.05)$.

3.2.4. Speed Test Results of the Two Groups before and after the Experiment. The sprint $(30 \mathrm{~m}, 60 \mathrm{~m}$, and $100 \mathrm{~m})$ test results of experimental group and control group are compared, as shown in Figure 4.

After the subjects are trained according to the formulated plan, the sprint scores of subjects in experimental group $(30 \mathrm{~m}, 60 \mathrm{~m}$, and $100 \mathrm{~m})$ increase from 3.87 to $3.72 \mathrm{~s}$, from 6.97 to $6.87 \mathrm{~s}$, and from 11.21 to $11.09 \mathrm{~s}$, respectively 


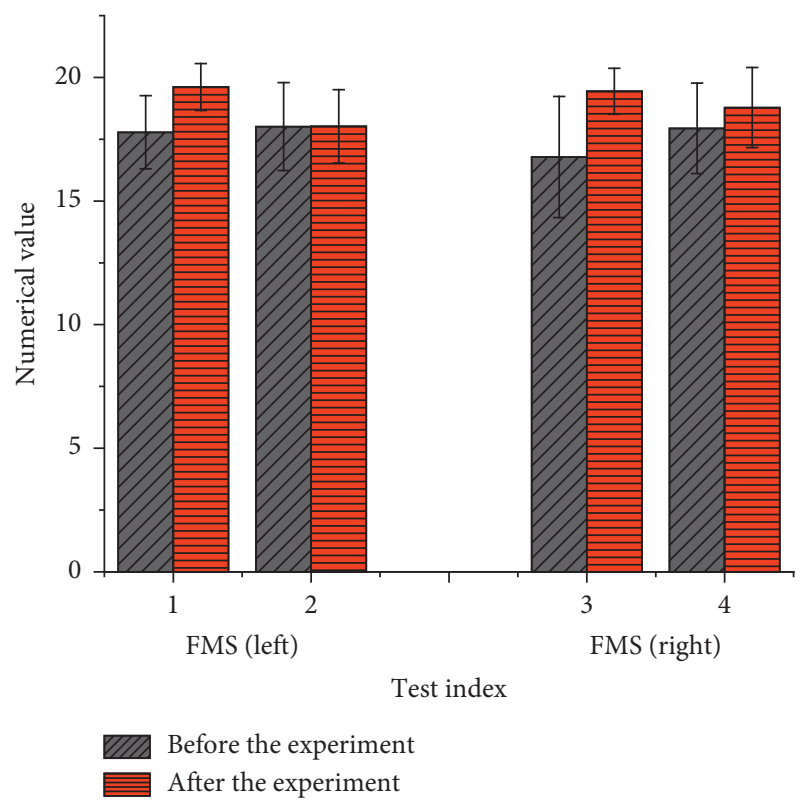

FIGURE 2: FMS test results of experimental group and control group before and after the experiment ( 1 and 3 represent before the experiment; 2 and 4 represent after the experiment).

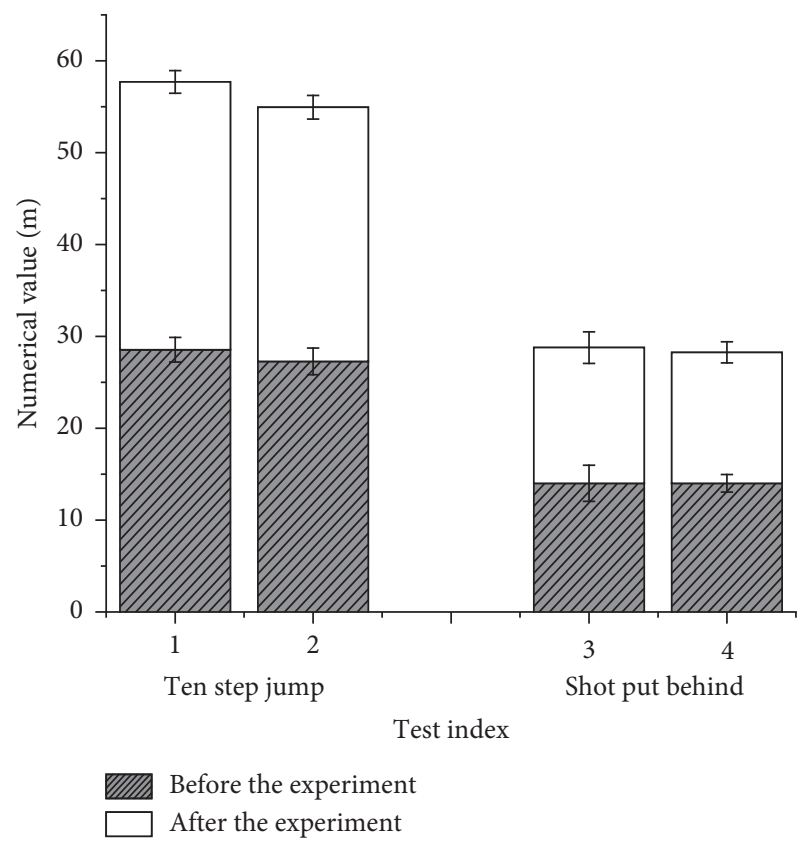

FIGURE 3: Level-ten stepping and postshot throw test results of experimental group and control group (1 and 3 represent before experiment; $2 \mathrm{a}$ and 4 represent after experiment.).

(Figure 4). There is a notable difference in comparison $(P<0.05)$. Under the traditional training program, experimental group and control group only have a remarkable difference in the $30 \mathrm{~m}$ training performance $(P<0.05)$, and there is no great difference in the $60 \mathrm{~m}$ and $100 \mathrm{~m}$ performance $(P>0.05)$. However, for the comparison between the

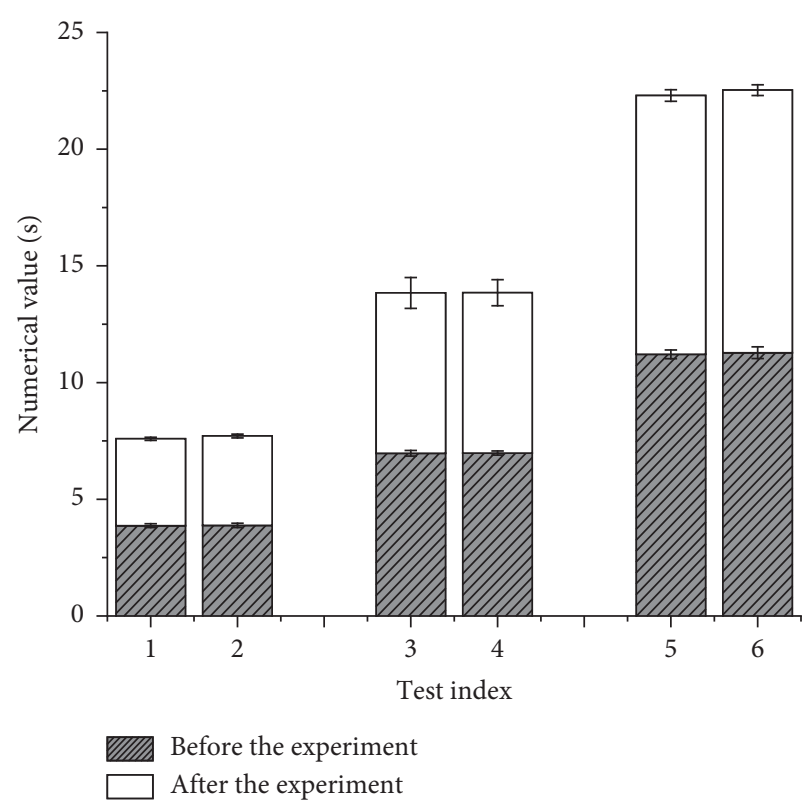

Figure 4: Test results of sprint $(30 \mathrm{~m}, 60 \mathrm{~m}$, and $100 \mathrm{~m})$ of experimental group and control group $(1,3$, and 5 represent before the experiment and 2, 4, and 6 represent after the experiment.).

two groups, there is a considerable difference between the $60 \mathrm{~m}$ and $100 \mathrm{~m}$ scores $(P<0.05)$.

\section{Conclusion}

The scientific mechanism of trunk support stability training is analyzed in this work so do the advantages of trunk support stability training, the physiological basis of trunk support stability training, and its biomechanical mechanism. Moreover, a trunk support stability training program is developed for sprint athletes, which focuses on the stability, strength, and balance of sprint athletes' shoulder, trunk, and buttocks musculature, as well as the training of limb control ability. Then, the test results of trunk support stability training are compared with those of traditional trunk strength training. From the results, both trunk support and stability training and traditional trunk strength training can improve subjects' FMS performance. There is no substantial difference between the two groups, but the improvement of experimental group is better relative to control group. For the strength test of subjects, only the level-ten stepping contrast between groups has a considerable difference, and the value of postshot throw before and after the experiment is very obvious. The speed difference between the two groups of subjects is very obvious, especially the $60 \mathrm{~m}$ and $100 \mathrm{~m}$ sprints. However, this work also has certain shortcomings. The experimental plan has a short period, and most of the students in sports colleges are national second-level athletes, which makes the results fail to reflect the actual situation of high-level athletes, and it needs to be analyzed in the follow-up research plans. 


\section{Data Availability}

Data sharing is not applicable to this article as no datasets were generated or analyzed during the current study.

\section{Conflicts of Interest}

The author(s) declare that there are no conflicts of interest with respect to the research, authorship, and/or publication of this article.

\section{References}

[1] M. Timme, J. M. Steinacker, and A. Schmeling, "Age estimation in competitive sports," International Journal of Legal Medicine, vol. 131, no. 1, pp. 225-233, 2017.

[2] J. S. Hamilton, N. S. Schutte, G. M. Moyle, and R. Brown, "The relationships between mindfulness, sport anxiety, pessimistic attributions and flow in competitive cyclists," International Journal of Sport Psychology, vol. 47, no. 2, pp. 103-121, 2016.

[3] N. Mascret, J. L. Falconetti, and C. Franois, "Conceptions of sport ability and practice of sport: an implicit measure," International Journal of Sport Psychology, vol. 47, no. 2, pp. 122-132, 2016.

[4] I. Mujika, A. P. Sharma, and T. Stellingwerff, "Contemporary periodization of altitude training for elite endurance athletes: a narrative review," Sports Medicine, vol. 49, no. 11, pp. 1651-1669, 2019.

[5] C. Paquette, E. Franzén, and F. B. Horak, "More falls in cerebellar ataxia when standing on a slow up-moving tilt of the support surface," The Cerebellum, vol. 15, no. 3, pp. 336-342, 2016.

[6] Z. F. Zheng, Y. S. Liu, X. Min, J. B Tang, H. W Liu, and B. Cheng, "Recovery of sympathetic nerve function after lumbar sympathectomy is slower in the hind limbs than in the torso," Neural Regeneration Research, vol. 12, no. 007, pp. 1177-1185, 2017.

[7] D. Wafa, B. Dugue, L. Vinches et al., "Cooling during exercise enhances performances, but the cooled body areas matter: a systematic review with meta-analyses," Scandinavian Journal of Medicine \& Science in Sports, vol. 29, no. 11, pp. 1660-1676, 2019.

[8] S. Y. Xia, Q. Zhan, and A. Rahmani, "ZMP based motion stability analysis of a wheeled humanoid robot with bending torso," Applied Mechanics and Materials, vol. 851, pp. 497502, 2016.

[9] P. Zhou, H. Cai, and C. Yang, "Stabilization of the unstable equilibrium points of the fractional-order BLDCM chaotic system in the sense of Lyapunov by a single-state variable," Nonlinear Dynamics, vol. 84, no. 4, pp. 2357-2361, 2016.

[10] J. L. RoryM Cc, A. J. Chambers, A. Daftary, and M. S. Redfern, "Torso kinematics during gait and trunk anthropometry in pregnant fallers and non-fallers," Gait \& Posture, vol. 76, pp. 204-209, 2019.

[11] V. K. Tjong, B. M. Devitt, M. L. Murnaghan, D. J. O. Harris, and J. S. Theodoropoulos, "A qualitative investigation of return to sport after arthroscopic bankart repair: beyond stability," The American Journal of Sports Medicine, vol. 43, no. 8, pp. 2005-2011, 2016.

[12] L. Stanciu, "Financial stability - fundamental pillar of macroeconomic balance and stability," International Conference Knowledge-Based Organization, vol. 25, no. 2, pp. 93-97, 2019.

[13] F. Giesche, J. Wilke, T. Engeroff et al., "Are biomechanical stability deficits during unplanned single-leg landings related to specific markers of cognitive function?" Journal of Science and Medicine in Sport, vol. 23, no. 1, pp. 82-88, 2020.

[14] A. Gayed, B. T. Bryan, K. Petrie et al., "A protocol for the HeadCoach trial: the development and evaluation of an online mental health training program for workplace managers," BMC Psychiatry, vol. 18, no. 1, p. 25, 2018.

[15] J. B. Farley, L. M. Barrett, J. W. L. Keogh, C. T. Woods, and N. Milne, "The relationship between physical fitness attributes and sports injury in female, team ball sport players: a systematic review," Sports Medicine - Open, vol. 6, no. 1, p. 45, 2020.

[16] L. Pereira, C. Winckler, C. C. C. Abad et al., "Power and speed differences between brazilian paralympic sprinters with visual impairment and their guides," Adapted Physical Activity Quarterly, vol. 33, no. 4, pp. 311-323, 2016.

[17] M. I. Khan, V. Santamaria, J. Kang et al., "Enhancing seated stability using trunk support trainer (TruST)," IEEE Robotics and Automation Letters, vol. 2, no. 3, pp. 1609-1616, 2017.

[18] I. Aoi, I. Aya, M. Saori, K. Aya, E. Kumiko, and F. Satoshi, "Comparison of site-specific bone mineral densities between endurance runners and sprinters in adolescent women," Nutrients, vol. 8, no. 12, p. 781, 2016.

[19] S. B. Ju and G. D. Park, "Effects of the application of ankle functional rehabilitation exercise on the ankle joint functional movement screen and isokinetic muscular function in patients with chronic ankle sprain," Journal of Physical Therapy Science, vol. 29, no. 2, pp. 278-281, 2017.

[20] M. Jeon, A. Jeon, and J. H. Lee, "Differences in body composition of upper and lower limbs in elite taekwondo athletes," International Journal of Morphology, vol. 38, no. 2, pp. 265-272, 2020. 